NO

ONE'S

WITNESS 
Black Outdoors Innovations in the Poetics of Study A SERIES EDITED BY J. KAMERON CARTER AND SARAH JANE CERVENAK 


\section{RACHEL ZOLF}
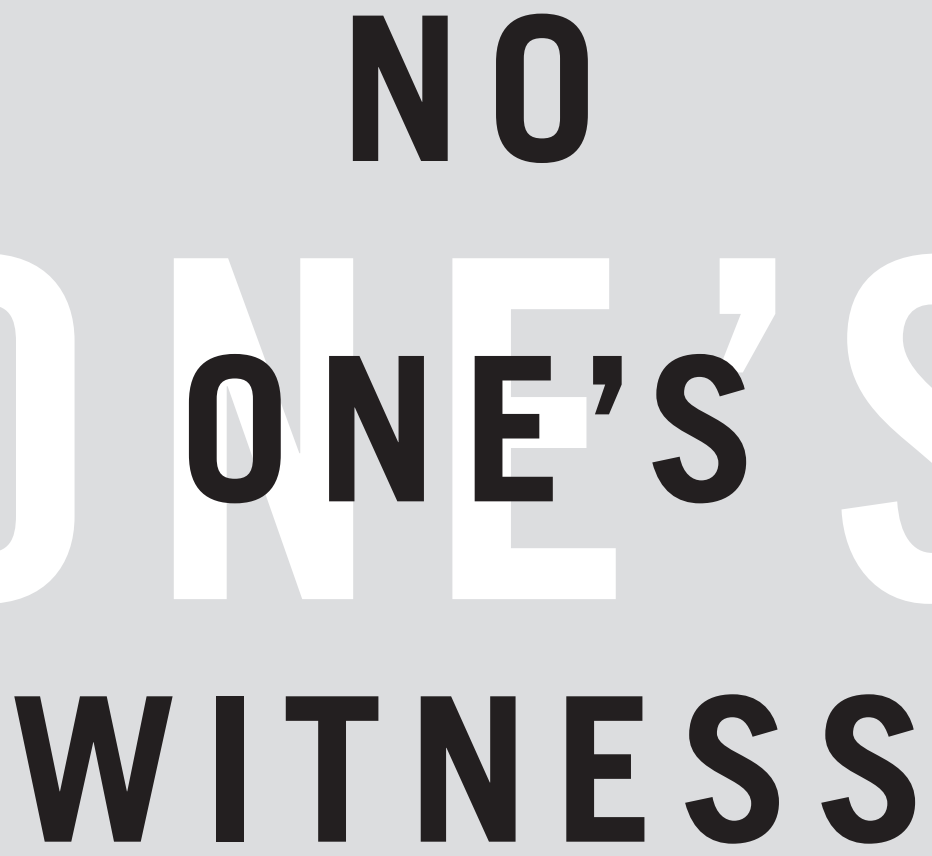

\section{A MONSTROUS POETICS}


(C) 2O2I DUKE UNIVERSITY PRESS

All rights reserved

Printed in the United States of America on acid-free paper $\infty$

Designed by: Matthew Tauch

Typeset in Portrait Text by Copperline Book Services

Library of Congress Cataloging-in-Publication Data

Names: Zolf, Rachel, [date] author.

Title: No one's witness : a monstrous poetics / Rachel Zolf.

Other titles: Black outdoors.

Description: Durham : Duke University Press, 202I. | Series: Black

outdoors | Includes bibliographical references and index.

Identifiers: LCCN 2020046228 (print) | LCCN 2020046229 (ebook)

ISBN 978I4780I3334 (hardcover)

ISBN 978I4780I4249 (paperback)

ISBN 978I47802155I (ebook)

Subjects: LCSH: Celan, Paul-Criticism and

interpretation. | German literature-Jewish authors-History

and criticism. | German literature-2oth century-History and crit-

icism. | Holocaust, Jewish (1939-I945), in literature. |

Psychic trauma in literature. | Poetics.

Classification: LCC PT2605.E4 Z978 202I (print) |

LCC PT2605.E4 (ebook) | DDC 8II/.54-dc23

LC record available at https://lccn.loc.gov/2020046228

LC ebook record available at https://lccn.loc.gov/2020046229

Cover art: James Allister Sprang, Concrete Color Arrangement \#I2, 20I7. Archival Ink Print. Courtesy of the artist. 